Motrivivência $\quad$ v. 26, n. 43, p. 89-103, dezembro/2014

\title{
REFLEXÕES SOBRE A PRÁTICA COMO COMPONENTE CURRICULAR DO CURSO DE LICENCIATURA EM EDUCAÇÃO FÍSICA DA UNIVERSIDADE FEDERAL DO MARANHÃO
}

\author{
Raffaelle Andressa dos Santos Araujo' \\ Meirecele Colíope Leitinho²
}

\begin{abstract}
RESUMO
Neste estudo, analisamos a Prática como Componente Curricular (PCC) no Curso de Licenciatura em Educação Física da Universidade Federal do Maranhão (UFMA), compreendida no currículo como espaço de articulação das dimensões teórica- prática na formação profissional. Optamos pelo estudo de caso, utilizando como coleta de dados pesquisa bibliográfica, análise documental e pesquisa de campo com entrevistas e levantamento estruturado dos professores e alunos deste Curso. Os resultados apontaram que a PCC não está desenvolvida tal como proposto em seu Projeto Pedagógico. Conclusivamente, essas dificuldades envolvem processos formativos específicos para os sujeitos que desenvolvem a PCC na área de Educação Física.
\end{abstract}

Palavras-chave: Formação; Licenciatura; Educação Física; Prática. Currículo

1 Doutoranda em Educação pela UECE. Docente do IFMA, Buriticupu/Maranhão, Brasil.

E.mail: raffaelle.araujo@ifma.edu.br

2 Pós-doutora pela UnB. Docente da UECE. Fortaleza/Ceará, Brasil.

E-mail: meirecele@terra.com.br 


\section{INTRODUÇÃO}

A reforma educacional iniciada pela Lei de Diretrizes e Bases da Educação Nacional (LDBEN) n. 9.394/96 (BRASIL, 1996), foi um marco político-institucional, que propôs diretrizes inovadoras para a organização e a gestão dos sistemas de ensino da educação básica e ela depois desencadeou-se em um processo de discussão sobre as Diretrizes Curriculares Nacionais (DCNs) para os cursos de graduação, via ordenamentos legais, entre os quais destaca-se o Parecer $n$. 09/2001 do Conselho Nacional de Educação/ Conselho Pleno - CNE/CP (BRASIL, 2001), que tratou em específico das DCNs para a formação de professores da Educação Básica, em nível superior, cursos de licenciaturas (graduação plena).

Neste cenário surge a pesquisa sobre a Prática como Componente Curricular (PCC) que deu origem a este estudo no âmbito da Universidade Federal do Maranhão (UFMA). Por toda a década de 90, a "prática" na matriz curricular do Curso de Licenciatura em Educação Física da UFMA encontrava-se reduzida ao "Estágio Curricular". Diante da necessidade de implementação de um novo Projeto Pedagógico (PP) para o Curso de Licenciatura em Educação Física da UFMA, a coordenação do referido Curso buscou atender às exigências da Resolução CNE/CP nº 2/02 (BRASIL, 2002), que recomenda a articulação teórico-prática, com quatrocentas horas (400h) de PCC, vivenciadas ao longo do curso.

O intuito deste estudo é ampliar a visão político, cultural, social, educativa e científica sobre a PCC; contribuindo para uma formação docente em Educação Física, com base numa relação dialética entre o conhecimento cientificamente produzido e as dimensões teorico-práticas descritas no currículo do Curso de Licenciatura em Educação Física da UFMA, numa perspectiva crítica.

O objetivo desta pesquisa foi analisar a PCC do Curso de Licenciatura em Educação Física da UFMA, compreendida no currículo dos cursos de licenciatura como espaço de ampliação da formação profissional. Para ampliar os referenciais teóricos de investigação, optamos por discutir a práxis (VÁZQUEZ, 1977), pressupondo a mútua dependência entre a teoria e a prática e nas discussões sobre a prática pedagógica (FONSECA, 2005; VEIGA, 2010; PIMENTA, 2011) e a PCC nos diferentes ordenamentos legais. Em um segundo momento, buscamos o entendimento da PCC no Curso de Licenciatura em Educação Física da UFMA, a partir do PP do referido curso, dos planos de ensino dos professores que contemplam essa prática curricular.

\section{A Prática como Componente Curricular: elementos conceituais}

A PCC nos cursos de formação de professores surgiu como componente curricular, inicialmente nas DCNs para a Formação de Professores, amparada por diferentes ordenamentos legais, como resoluções e pareceres, e, posteriormente, estendeu-se para a Educação Profissional de nível técnico e tecnológico. De acordo com o Parecer CNE/CES n 15/05 (BRASIL, 2005, p. 3), a PCC "é o conjunto de atividades formativas que proporcionam experiências de aplicação de conhecimentos ou de desenvolvimento de procedimentos próprios ao exercício da docência". No âmbito do ensino, os conhecimentos, as competências 
e as habilidades são adquiridas nas diversas atividades formativas que compõem o currículo do curso.

Conforme observamos nos documentos legais segundo a Resolução CNE/CP $n^{\circ}$ 2/02 (BRASIL, 2002), a PCC nos cursos de licenciatura encontra-se com uma carga horária de 400 horas mínimas, onde incita o desenvolvimento de projetos de ação pedagógica por parte dos alunos, em atuações no campo de trabalho do professor. As atividades caracterizadas pela PCC podem ser desenvolvidas através de núcleos, como parte de disciplinas ou de outras atividades formativas. Isto inclui as disciplinas de caráter prático, relacionadas à formação pedagógica, mas não aquelas referentes aos fundamentos técnico-científicos, correspondentes a uma determinada área do conhecimento. Essas formas de desenvolvimento da PCC em núcleos, como parte de disciplinas ou atividades formativas podem favorecer um intercâmbio de práticas e teorias que se entrecruzam e se complementam, numa perspectiva de melhorar a prática pedagógica do professor.

O homem comum só concebe a prática como prática-utilitária, a qual ele usa para satisfazer as necessidades imediatas da vida cotidiana. Já a "práxis" tem um caráter consciente e intencional, pois nela o homem compreende uma outra racionalidade da prática, ou seja, trata-se de uma prática dirigida por finalidades que são produtos da consciência e está imbricada no pensamento humano. Logo, a práxis é "[...] a atividade humana transformadora da realidade natural e humana" (VÁZQUEZ, 1977, p. 32).

Assim, a PCC é uma forma específica da "práxis"; é uma dimensão dirigida por objetivos, finalidades e conhecimentos, vista de forma mais ampla. Do mesmo modo que é um pressuposto importante da formação de professores, onde se torna elemento decisivo na dinâmica dos espaços educativos. Na visão de Fonseca (2005, p. 216),

A reflexão na e sobre a prática dos sujei-
tos na dinâmica escolar potencializam
as mudanças, as transformações das
práticas, de uma determinada cultura
escolar. Trata-se, portanto, de uma con-
cepção de prática pedagógica que pres-
supõe uma formação teórico-prática di-
ferenciada, mais ampla e diversificada.

Em outras palavras, a prática sócio pedagógica, que também se evidencia no exercício da PCC, não é um mero campo de aplicação de teorias. Não se trata de reduzir tudo à prática, nem tampouco de desvalorizar a dimensão teórica. Ela pressupõe uma relação teoria-prática que, segundo Veiga (2010, p. 17) assim se configura:

A finalidade da teoria pedagógica é
elaborar ou transformar idealmente,
e não realmente, a matéria-prima. O
lado objetivo da prática pedagógica é
constituído pelo conjunto de meios, o
modo pelo qual as teorias pedagógicas
são colocadas em ação pelo professor.
O que a distingue da teoria é o caráter
real, objetivo, da matéria-prima sobre a
qual ela atua, dos meios ou instrumen-
tos com que se exerce a ação, e de seu
resultado ou produto. Sua finalidade é
a transformação do real, objetiva, de
modo natural ou social, satisfazer deter-
minada necessidade humana.

De fato, a teoria e a prática não existem isoladamente. $\mathrm{Na}$ realidade, uma depende da outra e exercem uma influência mútua, ou seja, são dialetizadas. Quando a teoria se sobressai tende a limitar-se a posições idealistas; uma prática sem teoria, gera o ativismo, onde não se sabe o que pratica. 
A prática exige uma relação teórica de mútua dependência. Para Pimenta (2011, p. 93), a prática não existe "sem um mínimo de ingredientes teóricos", ela necessita conhecer a realidade para transformá-la e uma consciência, bem como o acesso a meios e utilização de técnicas de forma a gerar nova teoria a partir de diferentes práticas e assim sucessivamente.

A atividade profissional de todo professor, possui uma natureza pedagógica, pois se vincula a objetivos educativos de formação humana e a processos metodológicos e organizacionais de transmissão e apropriação de saberes e modos de ação. Por outro lado, é preciso levar em conta que todo conteúdo de saber, é resultado de um processo de construção de conhecimento.

\section{Reflexões sobre a PCC do Curso de Licen- ciatura em Educação Física da UFMA}

Procurando manter o "rigor científico $^{\prime 3}$ o estudo é de abordagem qualitativa em que utilizamos o método estudo de caso, cuja metodologia se desenvolveu a partir da triangulação de dados das pesquisas bibliográfica, documental e de campo, aplicando entrevistas semiestruturadas e questionários aos atores sociais desse processo: professores e alunos, respectivamente.

A análise documental consistiu na análise dos documentos do $\mathrm{CNE}^{4}$ e de outros documentos orientadores, que estruturaram o PP do Curso de Licenciatura em Educação Física da UFMA. Foram analisados os conteúdos destes documentos como também os Planos de Ensino das disciplinas, que contemplam a PCC; as entrevistas, do tipo semiestruturada, foram aplicadas ao coordenador, chefe de departamento e professores do curso e possibilitou explorações não previstas, dando liberdade aos entrevistados, para dissertarem sobre o tema, ou abordarem aspectos que sejam relevantes, sobre o objeto da investigação.

A entrevista contou com dois momentos distintos: um primeiro contato estabelecido com o professor, sujeito da pesquisa, para apresentar o propósito do estudo e formalizar o convite à participação e um segundo momento para assinatura do termo de consentimento livre e esclarecido e realização da entrevista.

O PP do Curso de Licenciatura em Educação Física da UFMA contempla quatorze disciplinas com PCC, ministradas por onze professores. Além do coordenador do curso e do chefe de departamento, participaram dessa pesquisa mais sete professores, totalizando nove professores, pois tanto o coordenador quanto o chefe de departamento também estavam ministrando disciplinas que contém a PCC, como parte de sua estruturação curricular. Também aplicamos questionários com doze alunos, correspondentes aos períodos intermediários e finais do Curso, tendo em vista o cumprimento da

3 Expressão utilizada para designar a consciência e preservação da coerência epistemológica (GHEDIN; FRANCO, 2008).

4 Parecer do CNE/CP 009/2001 de 8.05.2001 (BRASIL, 2001); Resolução CNE/CP 1, de 18.02.2002 (BRASIL, 2002) e Resolução do CNE/CP 2, de 19.02.2002 (BRASIL, 2002). 
maioria das disciplinas que contemplam a PCC nos períodos intermediários e em todas as disciplinas dos períodos finais.

Os professores e alunos pesquisados estão representados, neste estudo, por uma convenção de números e letras, e não pelos seus nomes. Tal estratégia se deu para preservar o anonimato dos participantes. Assim, passou a ser denominado o coordenador do curso como professor $\mathrm{C} 1$, o chefe de departamento como professor D1 e os demais professores como professor(a) P1, P2, P3, P4, P5, P6 e P7. Da mesma forma foi feito com os alunos, cuja convenção ficou determinada pelo número, atribuído de acordo com o período em que ele se encontra matriculado, e pela letra, para diferenciar cada participante.

Nessa perspectiva, organizamos a análise em seis categorias: a) Concepção de prática; b) Importância da PCC na formação inicial; c) Conhecimento sobre as informações da PCC; c) Desenvolvimento, acompanhamento e avaliação da PCC; d) Obstáculos na realização da PCC; e) Existência e superação da dicotomia entre teoria e prática.

Os resultados deste estudo estão apresentados nos quadros que se seguem.

\section{Dados da análise documental}

A PCC é denominada de prática pedagógica no decurso do PP do Curso de Licenciatura em Educação Física da UFMA (UFMA, 2007) e estão inseridas nos conteúdos das disciplinas, desenvolvidas durante todo o curso, em conformidade com as orientações das Resoluções CNE/CP $n^{\circ} 1 / 02$ e $n^{\circ} 2 / 02$ (BRASIL, 2002) de forma a garantir a articulação que necessita estar presente em todos os espaços acadêmicos, permeando toda a formação profissional, e permitindo que seu tempo e espaço não fiquem isolados e restritos ao estágio curricular supervisionado. Seguindo esse pressuposto, e de acordo com o PPP do curso (UFMA, 2007, p. 34), a prática:

[...] será vivenciada através de experiências de ensino (com os colegas da turma ou com a comunidade no horário da aula) ou na forma de projetos de extensão universitária (com a comunidade, fora do horário de aula) corresponde uma iniciativa da formação inicial que está inserida dentro de disciplinas de diferentes eixos curriculares ou como atividades curriculares complementares.

Coerentemente com a legislação vigente, a PCC no Projeto Político-Pedagógico do curso de licenciatura em Educação Física da UFMA, assumiu uma perspectiva de componente curricular denominada de "prática pedagógica" no contexto de quatorze disciplinas, que tiveram um acréscimo de trinta horas, para desenvolverem essa prática.

De início, percebemos que o PP do Curso de Licenciatura em Educação Física apresenta alterações positivas na matriz curricular, pois colocou a prática pedagógica ao longo do curso (com disciplinas do $1^{\circ}$ ao $6^{\circ}$ período) com a carga horária estabelecida pelas diretrizes, superando-a em vinte horas, totalizando $420 \mathrm{~h}$ (quatrocentas e vinte horas) de prática pedagógica.

Os artigos 13 e 14 da Resolução CNE/CP no 1/02 (BRASIL, 2002) tratam, respectivamente, de uma coordenação da dimensão prática e da construção de projetos inovadores e próprios para integrar os diversos eixos articuladores. Todavia, o PP do Curso de Licenciatura referenciado, apesar de enunciar essa informação, não 
expressa nenhuma indicação em seus escritos de como ela deve ser desenvolvida, e quais são as atribuições dessa coordenação. O PP apenas explicita uma articulação intrínseca da prática como componente curricular, com "o estágio supervisionado e com as atividades de trabalho acadêmico" (UFMA, 2007, p. 33) para a formação do futuro professor.

Segundo as DCNs (BRASIL, 2001), a coordenação da dimensão prática seriam as atividades inseridas em um espaço curricular de atuação coletiva e integrada dos formadores, com a finalidade de promover a articulação das diferentes práticas numa perspectiva interdisciplinar. Em relação à construção de projetos inovadores e específicos da PCC, o PP investigado não atende às orientações previstas pelos ordenamentos legais, pois não sugere ações para o desenvolvimento de atividades específicas de PCC para o exercício profissional.

Ainda nesse Projeto analisado, foram observadas algumas dificuldades: como a articulação das dimensões teóricas e práticas, não estando visível de que maneira e como essa articulação pode acontecer. Essa falta de clareza implicou, a nosso ver, no distanciamento da "práxis" à medida em que esse projeto se torna um "modismo" (VEIGA, 2010), levando-nos a uma concepção de educação estreita e imediatista, com caráter regulador e normativo, em conformidade com as orientações das reformas educacionais.

Os planos de ensino das disciplinas, que contemplam a PCC foram solicitados pela pesquisadora ao Departamento de Educação Física da UFMA, obtendo acesso apenas a quatro desses planejamentos de ensino, correspondentes aos professores C1, P6 e P7. Dos onze professores que ministram disciplinas de PCC, somente três professores tiveram o devido cuidado em entregar ao Departamento Acadêmico seus planejamentos, referentes ao primeiro semestre de 2011, sendo que o professor C1 entregou dois planos de ensino pelo fato de ministrar duas disciplinas de PCC. O professor P2 entregou, no momento da entrevista, apenas uma programação de todos os conteúdos que foram desenvolvidos no decorrer da disciplina.

Dessa forma, foram analisados quatro planos de ensino, e a programação de conteúdos do professor P2.

A PCC, embora apresentada de forma fragmentada, está presente nos planos de ensino com algumas divergências:

a) O plano é um "guia de orientação" (LIBÂNEO, 1994), onde são estabelecidas as diretrizes e os meios de realização do trabalho docente. Os planos analisados não contemplam a estrutura e os meios de realização da PCC;

b) Os planos não expressam uma ordem sequencial lógica de seus componentes, a fim de alcançar os objetivos, pois a PCC, quando apresentada, fica restrita a um componente do plano de ensino, não integrada a outros componentes;

c) A coerência favorece o diálogo entre as ideias, os componentes do plano e a prática. O professor tem o plano como oportunidade de reflexão e avaliação da sua prática. Para isso, é imprescindível a consistência e coesão entre seus elementos.

Assim, a tarefa do professor, de revisar e atualizar esse plano de ensino torna-se quase que utópica para os que não têm o hábito de planejar suas atividades 
docentes. Esta tarefa também é difícil para os que planejam de forma descontextualizada da realidade, acarretando uma desordem e incoerência nos seus componentes.

\section{O que dizem os professores e os alunos?}

Perfil dos Professores

A construção da identidade docente é um processo contínuo, que tem como base os saberes da experiência construídos no exercício profissional, mediante o ensino das áreas de conhecimento. Segundo Pimenta e Anastasiou (2010), a identidade dos professores é epistemológica e profissional. É epistemológica porque permite uma análise crítica dos saberes da experiência, construídos nas práticas, confrontando-os e ampliando-os com base no campo teórico da educação. Mas também é profissional, pois se constitui um campo específico de intervenção na prática social.

Os professores e alunos pesquisados estão representados por uma convenção de números e letras e não pelos seus nomes. Tal estratégia se deu para preservar o anonimato dos participantes, conforme aponta o termo de consentimento livre e esclarecido aplicado. Assim, passou a ser denominado o coordenador do curso como professor $\mathrm{C} 1$, o chefe de departamento como professor D1 e os demais professores como professor/ professora P1, P2, P3, P4, P5, P6 e P7. Da mesma forma foi feito com os alunos, cuja convenção ficou determinada pelo número, atribuído de acordo com o período em que ele se encontrava matriculado, e pela letra, para diferenciar cada participante.

Quadro 1: Perfil dos professores pesquisados.

\begin{tabular}{|c|c|c|c|}
\hline Dujeitos & Titulação & $\begin{array}{c}\text { Tempo de } \\
\text { profissão }\end{array}$ & $\begin{array}{c}\text { Tempo de } \\
\text { exercício na } \\
\text { UFMA }\end{array}$ \\
\hline $\begin{array}{c}\text { Professor C1 } \\
\text { (Coordenador) }\end{array}$ & Doutor em Educação (UFRN) & 25 anos & 15 anos \\
\hline $\begin{array}{c}\text { Professor D1 } \\
\text { (Chefe de } \\
\text { Departamento) }\end{array}$ & $\begin{array}{c}\text { Doutor em Fisiologia do Exercício em } \\
\text { Pneumopatas (Escola Paulista de } \\
\text { Pneumologia) }\end{array}$ & 19 anos & 2 anos \\
\hline Professora P1 & $\begin{array}{c}\text { Especialista em Ginástica Artística } \\
\text { e Dança (ESEF-PA) }\end{array}$ & 34 anos & 30 anos \\
\hline Professor P2 & Doutor em Educação (UNESP-Marília) & 17 anos & 10 anos \\
\hline Professora P3 & $\begin{array}{c}\text { Mestre em Motricidade Humana } \\
\text { (UNESP - Rio Claro) }\end{array}$ & 23 anos & 7 anos \\
\hline Professor P4 & Doutor em Psicologia Social (PUC-SP) & 36 anos & 30 anos \\
\hline Professor P5 & $\begin{array}{c}\text { Doutor em Ciências Biomédicas (USP) } \\
\text { meses }\end{array}$ \\
\hline Professor P6 & $\begin{array}{c}\text { Mestre em Lazer e Desenvolvimento Local } \\
\text { (Universidade de Coimbra) }\end{array}$ & 24 anos & 8 meses \\
\hline Professor P7 & Especialista em Metodologia do Ensino & 26 anos & 26 anos \\
\hline
\end{tabular}

Fonte: Pesquisa, 2011 
No que tange ao desenvolvimento profissional do docente, um exame inicial dos dados empíricos, o qual define o perfil dos professores pesquisados (Quadro 1), permitiu constatar que a maioria dos professores entrevistados possui pós-graduação, sendo 55,56\% com Doutorado, 22,22\% com Mestrado e 22,22\% com Especialização. As áreas escolhidas pelos professores se concentram em: Educação, Fisiologia do Exercício, Ginástica Artística, Motricidade Humana, Psicologia Social, Ciências Biomédicas, Lazer e Desenvolvimento Local.

No que se refere à experiência profissional, $77,78 \%$ dos professores já exerceram funções na educação básica, 11,11\% com experiência unicamente no Ensino Superior e $11,11 \%$ com experiência em clubes e academias. Observamos que a ação pedagógica do professor de Educação Física, em exercício docente se materializa em diferentes campos de atuação, conforme o Parecer CNE/CES no 400/05 (BRASIL, 2005).

Pode-se afirmar que os diversos campos profissionais de Educação Física são oriundos da própria natureza dessa área de conhecimento, cujas atividades e processos desenvolvem a natureza biofísica do homem e, também, fundamentalmente, sua natureza humana. De igual maneira, as experiências nessa área de ensino são únicas e refletem a valorização identitária dos professores.

Em relação ao tempo de profissão, os professores entrevistados possuem entre 15 e 36 anos de experiência. Quanto ao exercício profissional na UFMA, observamos uma boa média, praticamente igualada à fundação do curso de licenciatura em Educação Física da UFMA, sendo 55,56\% dos professores entre 25 e 30 anos de experiência.
A Educação Física passou por uma crise de identidade de seus pressupostos epistemológicos durante o final da década de 1970 e início da década de 1980, e sob a influência das teorias críticas da educação, o campo de debates e discussões cresceu em relação ao seu papel e sua dimensão política no contexto escolar, contrapondo às perspectivas tecnicista, esportivista e biologicista. Como verificamos, mais da metade dos professores iniciaram a docência na UFMA nesse cenário, praticamente com a implantação do curso de licenciatura em Educação Física, que foi criado em 1977.

$\mathrm{E}$, nesse sentido, é preciso compreender que as diferentes concepções e referências teóricas da Educação Física, nessas três últimas décadas, enfatizaram basicamente os procedimentos metodológico-didáticos. Do mesmo modo, a prática pedagógica desses professores se concretizou nesses determinantes históricos. Após a identificação do perfil dos professores, vamos para a análise dos dados coletados nas entrevistas.

\section{A PCC na visão dos professores e alunos}

É importante compreender que a teoria e a prática são fundamentais para a ação pedagógica do professor. Esta deve ser intencionalmente definida e comprometida, pois a prática pedagógica pressupõe essa relação íntima da teoria com a prática, tendo em vista que o conhecimento ocorre no bojo do processo histórico e coletivo da práxis (VEIGA 2010; FONSECA, 2005; PIMENTA, 2011).

Apesar dos depoimentos dos professores em geral compreenderem a concepção de prática (ver Quadro 2) relacionada 
a indissociabilidade da teoria com a prática, constatamos que a maioria ainda não tem conhecimento do que é a PCC e sua importância para a formação inicial.

Quadro 2: Concepção de prática na visão dos professores

\begin{tabular}{|c|c|}
\hline Professor & Concepção de prática \\
\hline Professor D1 & $\begin{array}{c}\text { A prática vai reforçar o conhecimento teórico discutido em sala de aula, } \\
\text { aprendido teoricamente e da própria prática eu rediscuto essa teoria. }\end{array}$ \\
\hline Professor P2 & A relação teoria e prática são muito íntimas. \\
\hline Professor P4 & $\begin{array}{r}\text { Ela é uma dimensão ampla e contempla necessariamente uma prática crítica, } \\
\text { consciente, contextualizada que pressupõe conhecimento teórico. }\end{array}$ \\
\hline Professor P7 & A prática não existe sem a teoria. \\
\hline
\end{tabular}

Fonte: Pesquisa, 2011

Identificamos nas falas dos professores que eles não sabem quantas e quais são as disciplinas de PCC, desconhecem as informações do PP do Curso (UFMA, 2007), dividem, aleatoriamente, a PCC em quinze horas presenciais e quinze horas não presenciais, percebem a ausência de discussão entre os professores de PCC, e a inexistência de um projeto específico de PCC.

Esses problemas, de certa forma, contribuem para a dicotomia entre teoria e prática, ao evidenciarem aulas teóricas e aulas práticas como se fossem PCC. As aulas práticas, que são muito frequentes na Educação Física, visam permitir o contato com as diversas práticas corporais, de forma que o aluno (futuro professor) aprenda os fundamentos e princípios básicos em cada conteúdo. Como a PCC inclui as aulas de caráter prático, relacionadas à formação pedagógica, a nossa percepção é que estas devem ser planejadas e atuarem na formação da identidade do professor como educador, o que não se resume apenas na transmissão de teorias para guiar um fazer pedagógico.

É nosso entendimento, que as manifestações das diferentes expressões da cultura corporal não podem ser confundidas com a PCC. A aula prática por si só, não pode ser caracterizada como uma prática pedagógica ou PCC, pois esta deve ser devidamente planejada e desenvolvida na formação da identidade do futuro professor, o que não se resume na transmissão de teorias para viabilizar simplesmente um fazer pedagógico destituído de uma reflexão teórica. A PCC expressa o exercício da docência em tempo e espaço curricular específico, visando à atuação em situações contextualizadas de ensino e aprendizagem (BRASIL, 2001).

Quanto aos alunos, os dados indicam que eles atribuem a importância da PCC, as diferentes experiências em situações reais de aprendizagem, acreditando que ela possibilita uma melhor compreensão das teorias estudadas em sala de aula (ver Quadro 3). 
Quadro 3: Importância da PCC para a formação inicial na visão dos alunos

\begin{tabular}{|l|l|}
\hline Aluno & Importância da PCC para a formação inicial \\
\hline Aluno $5^{\mathrm{a}}$ & $\begin{array}{l}\text { É uma forma de preparo, experiência para situações que provavelmente } \\
\text { aconteçam quando eu estiver atuando profissionalmente. }\end{array}$ \\
\hline Aluno 5C & $\begin{array}{l}\text { Ter uma visão diferente da realidade do mundo fora da universidade, } \\
\text { entendendo que terá condições e até conflitos durante suas aulas. }\end{array}$ \\
\hline Aluna $6^{\mathrm{a}}$ & $\begin{array}{l}\text { Os conhecimentos práticos possibilitam maiores entendimentos e melhores } \\
\text { interpretações das teorias estudadas durante a formação. }\end{array}$ \\
\hline Aluno 9C & $\begin{array}{l}\text { Permitir ao aluno perceber quais dificuldades, facilidades e prováveis desafios que } \\
\text { virá encontrar fora dos muros da universidade, ou melhor dos bancos universitários. }\end{array}$ \\
\hline
\end{tabular}

Fonte: Pesquisa, 2011

Apesar dessa orientação apresentada na Resolução CNE/CP no 2/02 (BRASIL, 2002), identificamos nas categorias desenvolvimento, acompanhamento e avaliação da PCC que os professores, em sua maioria, desenvolvem a PCC através de experiências de ensino com os próprios colegas da turma, na forma de microaulas, fato este confirmado também pelos alunos (ver Quadro 4).

Quadro 4: Atividades de PCC desenvolvidas nas disciplinas

\begin{tabular}{|l|l|}
\hline Professor & Atividades de PCC \\
\hline Professor P4 & Micro-aulas na qual vou intervir depois do processo. \\
\hline Professor P5 & Ele tem que ministrar aulas para os próprios colegas. \\
\hline Professora P3 & $\begin{array}{l}\text { Fazemos o planejamento das atividades práticas, eles vão para a escola, } \\
\text { realizam as atividades e depois apresentam o relatório. }\end{array}$ \\
\hline Professor P6 & $\begin{array}{l}\text { Oficinas que eu vou trabalhar na disciplina ministrando e/ou convidando } \\
\text { professores de fora. }\end{array}$ \\
\hline Professora C1 & Micro-aulas e produção de material didático. \\
\hline
\end{tabular}

Fonte: Pesquisa, 2011

Conforme dados apresentados no quadro acima, além das microaulas, os professores utilizam a participação em oficinas, a elaboração de relatórios e a produção de material didático. Os alunos, ao relatarem as principais atividades de PCC confirmam as falas dos professores acrescentando as atividades de elaboração de artigos científicos e seminários. Entretanto, ao afirmar a participação em projetos de pesquisa e extensão como atividades de PCC, demonstram não compreenderem a diferença entre a PCC e as Atividades Complementares presentes nos PP do Curso (UFMA, 2007).

A carga horária, conforme descrita anteriormente, também gera diferentes entendimentos por parte dos professores. Vale ressaltar que o PP do curso contempla apenas a divisão de "60 + 30", sendo sessenta horas da disciplina e trinta de 
prática pedagógica e, alguns professores redistribuem às trinta horas em duas etapas sendo quinze horas presenciais sob a responsabilidade do professor e quinze horas não presenciais sob a responsabilidade do aluno extra horário da disciplina. Apesar dos professores reconhecerem a necessidade de articulação/interação entre as disciplinas de PCC, pouco foi feito desde a implantação das PCCs em 2007 para minimizar essa distância. No entanto, o que está delineado no PP do Curso, como os seminários entre as diferentes disciplinas que contemplam a PCC, não se concretiza na prática.

Como não existe um planejamento coletivo dos professores e nem supervisão, a PCC fica de inteira responsabilidade do professor em ofertar, planejar, discutir e avaliar todo o processo. Dessa forma, sugerimos à coordenação do Curso de Licenciatura em Educação Física da UFMA a realização de seminários da disciplina (interno) e entre as disciplinas (externo) de PCC em cada semestre, para possibilitar a troca de experiências proposta no PP do Curso e diminuir os desencontros expressos nos depoimentos de professores(as) e alunos(as) entrevistados(as). Do mesmo modo, registramos a necessidade urgente na elaboração de normas complementares que favoreçam o entendimento da comunidade acadêmica sobre a aplicabilidade da PCC nas diferentes disciplinas do Curso de Licenciatura em Educação Física da UFMA, tendo em vista que as ideias alicerçadas numa teoria sistematizada favorecem a ação pedagógica do professor no desenvolvimento da PCC (PIMENTA, 2011).

Quanto aos obstáculos na realização da PCC, observamos uma dissonância entre professores e alunos. Os professores afirmam não perceberem o entendimento e valorização da PCC por parte dos alunos. E os alunos relatam que a maioria dos professores não realizam a PCC segundo os dados que se segue (ver Quadro 5).

Quadro 5: Principais obstáculos na realização da PCC na visão dos alunos

\begin{tabular}{|l|l|}
\hline Aluno & Principais obstáculos \\
\hline Aluno 5B & $\begin{array}{l}\text { A falta de empenho de muitos professores que acreditam que para a prática basta } \\
\text { uma apresentação de seminário. }\end{array}$ \\
\hline Aluno 8 & Falta de estrutura, recursos e interesse de muitos alunos. \\
\hline Aluno 8B & Capacitar os docentes sobre o que é de fato e como aplicar a PCC. \\
\hline Aluno 8C & $\begin{array}{l}\text { A PCC não é discutida em sala de aula e nem tampouco esclarecidas no curso } \\
\text { de formação. }\end{array}$ \\
\hline Aluno 9A & $\begin{array}{l}\text { Não realização da PCC por parte da maioria dos professores e, por conseguinte a } \\
\text { acomodação dos alunos. }\end{array}$ \\
\hline Aluno 9B & A dicotomia e a interpretação que os professores atribuem a PCC. \\
\hline
\end{tabular}

Fonte: Pesquisa, 2011

Ao longo desse estudo, encontramos alguns professores e alunos conscientes de suas próprias falhas: professores afirmam terem dificuldades em desenvolverem a
PCC e reconhecem que o desafio maior está nele mesmo, e essa dificuldade acaba influenciando o aluno. O mesmo acontece com alguns alunos, que reconhecem suas 
limitações como a falta de interesse, despreparo e a acomodação. Por outro lado, detectamos que existe a "falta" de local para desenvolver essas práticas, e o despreparo e a falta de interesse de muitos alunos que resulta na não realização da PCC conforme prevê o PP do curso (UFMA, 2007). Como conseqüência, temos a não realização, da maioria das práticas pedagógicas propostas e, quando realizadas, desprovida de qualquer reflexão crítica.

Os dados do estudo nos permite compreender a teoria e a prática como elementos indissolúveis, de forma a reconhecer uma relação dialetizada (VÁZQUEZ, 1977; VEIGA 2010; FONSECA, 2005; PIMENTA, 2011). Isso implica na compreensão do processo de ensino em suas várias determinações e na busca de caminhos alternativos para viabilizar uma prática pedagógica mais consciente.

Em relação à existência e superação da dicotomia entre a teoria e a prática os professores entrevistados, afirmaram que existe essa dicotomia, por perceberem que o discurso e a prática muitas vezes se distanciam na sua operacionalização. Entendemos, então, que a teoria, tende a se tornar um acúmulo de informações distanciadas da prática refletida, impedindo, dessa forma, uma relação dialética, que traz benefícios nas contradições e imprevisibilidades que a realidade possibilita.

\section{CONCLUSÃO}

De modo geral, os sujeitos investigados afirmaram a existência da dicotomia teoria/prática na PCC e acreditam que a PCC tem contribuído de maneira significativa para a superação dessa dicotomia. Entretanto, algumas falas de professores apontaram diferentes interpretações pedagógicas que variam de acordo com sua concepção. Se o docente não tem claramente a visão de que a concepção de formação, deve estar pautada numa formação reflexiva, onde o aluno, futuro professor, deve aprimorar e reelaborar continuamente seus conhecimentos, ele vai simplesmente reproduzir práticas pedagógicas descontextualizadas, dissociando teoria e prática.

Podemos afirmar que, a partir das categorias analisadas (concepção de prática; importância da PCC na formação inicial; conhecimento sobre as informações da PCC; desenvolvimento, acompanhamento e avaliação da PCC; obstáculos na realização da PCC; existência e superação da dicotomia entre teoria e prática) o Curso de Licenciatura em Educação Física da UFMA, necessita viabilizar a organização das informações sobre a PCC, descritas no PP do Curso (BRASIL, 2007) e discutir a não apropriação por parte dos professores sobre o conhecimento de que trata a PCC. A indicação da ausência de planejamento das práticas pedagógicas de praticamente todos os professores entrevistados e à não articulação de outros elementos, resulta em uma dissociação entre o que está escrito e oficializado, e o que é percebido e vivenciado pelos professores e alunos no interior das disciplinas de PCC.

A realidade das disciplinas de PCC no referido curso, embora não esteja sendo aplicada com êxito, tem contribuído para a busca consciente de superação da dicotomia entre teoria e prática; entretanto, ainda há a necessidade de que esse tipo de prática seja mais contextualizada, crítica e reflexiva. Estes resultados nos permite afirmar, que demos um passo significativo para superar 
lacunas na forma de organização e desenvolvimento da Prática como Componente Curricular, e que essas dificuldades, não são apenas de caráter interpretativo, elas envolvem processos formativos específicos para professores, alunos e coordenadores de cursos, que são os sujeitos responsáveis pelo seu desenvolvimento, como de atividades importantes para a formação do professor de Educação Física.

\section{REFERÊNCIAS}

BRASIL. Lei $\mathbf{n}^{\circ} \mathbf{9 . 3 9 4}$, de 20 de dezembro de 1996. Estabelece as Diretrizes e Bases da Educação Nacional. Disponível em: < http://www.planalto. gov.br/ccivil_03/leis/l9394.htm > . Acesso em: 27 ago. 2014.

. Ministério da Educação (MEC). Conselho Nacional de Educação (CNE). Conselho Pleno. Parecer n. 009, de 8 de maio de 2001. Diretrizes Curriculares Nacionais para a Formação de Professores da Educação Básica, em nível superior, curso de licenciatura, de graduação plena. Brasília. 2001. Disponível em: < http://portal.mec.gov. $\mathrm{br} / \mathrm{cne} /$ arquivos/pdf/009.pdf $>$. Acesso em: 15 ago. 2014.

. Ministério da Educação (MEC). Conselho Nacional de Educação (CNE). Parecer n. 15 de 02 de fevereiro de 2005. Solicitação de esclarecimento sobre as Resoluções CNE/CP $\mathrm{n}^{\circ} \mathrm{S} 1 / 2002$, que institui Diretrizes Curriculares Nacionais para a Formação de Professores da Educação Básica, em nível superior, curso de licenciatura, de graduação plena, e 2/2002, que institui a duração e a carga horária dos cursos de licenciatura, de graduação plena, de Formação de Professores da Educação Básica, em nível superior. 2002. Disponível em: < http://portal.mec. gov.br/cne/arquivos/pdf/pces0015_05. pdf > . Acesso em: 25 ago. 2014.

. Resolução n. 1, de 18 de fevereiro de 2002. Institui as Diretrizes Curriculares Nacionais para a Formação de Professores da Educação Básica, em nível superior, curso de licenciatura, graduação plena. Brasília, 2002. Disponível em: < http://portal.mec.gov. $\mathrm{br} / \mathrm{cne} /$ arquivos/pdf/009.pdf $>$. Acesso em: 10 set. 2014.

Resolução n. 2, de 19 de fevereiro de 2002. Institui a duração e a carga horária dos cursos de licenciatura, de graduação plena, de formação de professores da educação básica em nível superior. Brasília. Disponível em: $<$ http://portal.mec.gov.br/cne/arquivos/ pdf/CP022002.pdf>. Acesso em: 10 set. 2014.

GHEDIN, Evandro; FRANCO, Maria Amélia Santoro. Questões de método na construção da pesquisa em educação. São Paulo: Cortez, 2008.

VEIGA, Ilma Passos Alencastro. A prática pedagógica do professor de didática. Campinas, SP: Papirus, 2010.

LIBÂNEO, José Carlos. Didática. São Paulo: Cortez, 1994.

SILVA, Luzimar Barbalho da. Formação Docente: a difícil tarefa de articular teoria e prática no campo curricular. In: CABRAL NETO, Antônio et al. (Orgs.). Pontos e contrapontos da política educacional: uma leitura contextualizada de iniciativas governamentais. Brasília: Líber Livro Editora, 2007.

FONSECA, Selma Guimarães. Saberes e práticas pedagógicas na formação 
inicial do professor para o ensino de história: vivências e recriações. In: ROMANOWSKI, Joana Paulin et al. (Orgs.). Conhecimento local e conhecimento universal: formação docente, aprendizado e ensino. Curitiba: Champagnat, 2005.

PIMENTA, Selma Garrido; ANASTASIOU, Léa das Graças Camargo. Docência no Ensino Superior. São Paulo: Cortez, 2010.
PIMENTA, Selma Garrido. O estágio na formação de professores: unidade teoria e prática? 10. Ed. São Paulo: Cortez, 2011.

UNIVERSIDADE FEDERAL DO MARAnhão. Projeto PolíticoPedagógico do Curso de Licenciatura em Educação Física. Núcleo de Esportes. São Luís, MA. 2007.

VÁZQUEZ, Adolfo Sánchez. Filosofia da práxis. 2. ed. Tradução Luiz Fernando Cardoso. Rio de Janeiro: Paz e Terra. 1977.

REFLECTIONS ON THE PRACTICE AS A COMPONENT OF CURRICULUM COURSE BACHELOR OF PHYSICAL EDUCATION UNIVERSITY FEDERAL MARANHÃO

\begin{abstract}
In this study, we analyze the practice as Curricular Component (PCC) in the Bachelor of Physical Education, Federal University of Maranhão (UFMA), understood in the curriculum as a space for articulation of theoretically dimensions practice in vocational training. We chose the case study, using survey data collection as bibliographical, documentary analysis and field survey and structured interviews with teachers and students of this course survey. The results showed that the PCC is not developed as proposed in his Pedagogical Project. Conclusively, these problems involve specific training processes for subjects who develop the PCC in the area of Physical Education.
\end{abstract}

Keywords: Training; Degree; Physical Education; Practice; Resume 
V. $26, n^{\circ} 43$, dezembro/2014

\section{REFLEXIONES SOBRE LA PRÁCTICA COMO COMPONENTE CURRICULAR DEL CURSO DE LICENCIATURA EN EDUCACIÓN FÍSICA DE LA UNIVERSIDAD FEDERAL DE MARANHÃO}

\section{RESUMEN}

En este estudio, analizamos la Práctica como Componente Curricular (PCC) en el Curso de Licenciatura en Educación Física de la Universidad Federal de Maranhão (UFMA), comprendida en el currículo como espacio de articulación de las dimensiones teóricapráctica en la formación profesional. Optamos por el estudio de caso, utilizando como colecta de datos investigación bibliográfica, análisis documental e investigación de campo con entrevistas y levantamiento estructurado de los profesores y alumnos de este Curso. Los resultados apuntaron que la PCC no está desarrollada tal como propuesto en su Proyecto Pedagógico. Conclusivamente esas dificultades envuelven procesos formativos específicos para los sujetos que desarrollan la PCC en el área de Educación Física.

Palabras clave: Formación; Licenciatura; Educación Física; Práctica; Currículo

Recebido em: agosto/2014 Aprovado em: novembro/2014 